\title{
Momento de cuidar: momento de reflexão na ação
}

\author{
Caring moment: moment of reflection in action
}

Momento de cuidar: momento de reflexión en la acción

\author{
Vera Regina Waldow' \\ 'Universidade Federal do Rio Grande do Sul. Escola de Enfermagem. Porto Alegre, RS
}

Submissão: $03 / 12 / 2008$

Aprovação: 28/12/2008

\section{RESUMO}

A reflexão-na-ação significa pensar o Que se faz enQuanto se está fazendo. O presente trabalho analisa esta atividade por parte do profissional de enfermagem tendo em vista o momento de cuidar, Que constitui o encontro entre ser que cuida e ser Que é cuidado. É sugerido Que a prática reflexiva seja estimulada durante o processo de formação e para tal, docentes devem estar preparados. A prática reflexiva apresenta vantagens tais como: atualização, renovação, geração de conhecimentos, entre outras.

Descritores: Cuidados de enfermagem; Enfermagem; Ensino.

\section{ABSTRACT}

Reflection-in-action means to think what we do while we are doing. The present text analyzes this activity on the part of the nurse professional considering the caring moment, which constitutes the encounter between the caregiver and the cared for. It is suggested that the reflective practice be stimulated during the educational process and for that, faculty must be prepared. The reflective practice presents advantages such as: updating, renewal, knowledge generation, among others.

Descriptors: Nursing care; Nursing; Teaching.

\section{RESUMEN}

La reflexión-en-la-acción significa pensar en lo Que se hace mientras se hace. El presente trabajo analiza esta actividad por parte del profesional enfermero teniendo en vista el momento de cuidar, Que constituye el encuentro entre el ser Que cuida y el ser Que es cuidado. Es sugerido Que la práctica reflexiva sea estimulada durante el proceso de formación y para tal, docentes deben estar preparados. La práctica reflexiva presenta ventajas tales como: actualización, renovación, generación de conocimiento, entre otras.

Descriptores: Atención de enfermería; Enfermería; Enseñanza. 


\section{INTRODUÇÃO}

A reflexão sobre a prática profissional e do ensino têm obtido maior interesse conforme se constata pela literatura mais recente ${ }^{(1,2)}$.

A necessidade de usar a reflexão como ferramenta ou como auxílio para rever a própria prática na enfermagem, seja no âmbito do ensino ou sobre o cuidado, iniciou com alguns poucos trabalhos no final da década de 80 e inicio da década de $90^{(3-6)}$. Após, observa-se uma lacuna, até mais recentemente como já referido.

Pesquisas e estudos em outras realidades nos brindam com interessantes e inspiradores resultados Que, apesar de enfocar diferentes metodologias, conduzem à reflexão da prática de enfermagem e têm, seguramente, implicações importantes na esfera do ensino ${ }^{(7-9)}$.

Ao se falar em refletir sobre a prática é necessário destacar os trabalhos de Schön ${ }^{(10,1)}$ Que, com certeza têm influenciado vários dos autores já mencionados Que tratam do assunto. Ele oferece variações sobre um ensino prático reflexivo e apresenta algumas idéias a partir das Quais se concretiza a prática reflexiva: conhecimento-na-ação, reflexão-na-ação e reflexão sobre a reflexão na ação.

O autor coloca Que "o ensino prático reflexivo é um ensino prático voltado para ajudar estudantes a adeuirirem os tipos de talento artístico essenciais para a competência em zonas indeterminadas da prática"(11).
Refletir a prática significa pensar sobre o Que se faz e a proposta de Schön é essencialmente pensar o que se faz enquanto se está fazendo.

$\mathrm{Na}$ Enfermagem existe uma proposta interessante de se refletir a prática, especialmente a do campo clínico, e tem como meta ver o mundo (da enfermagem, do cuidado) de forma diferente de como vinha sendo feito. Com base em novos insights, novas perspectivas, pode-se agir de forma diferente. Na verdade, a proposta é a de Que ao refletir sobre a prática, podemos vir a transformá-la ${ }^{(12)}$.

Alguns autores são específicos ao enfocar a reflexão da prática, privilegiando o cuidado, tido como objeto do agir profissional ou sua essência, como preferem outros ${ }^{(13,14)}$.

No presente trabalho busca-se esclarecer como poderia ocorrer a reflexão no momento de cuidar, ou seja, Quando a cuidadora realiza algum tipo de ação com o ser cuidado e Que se idealiza como sendo uma reflexão-na-ação.

O momento de cuidar - momento de encontro entre ser que cuida e ser Que é cuidado será analisado destacando-se a reflexão Que é prevista deveria ocorrer por parte da cuidadora e que pode ser visualizado na Figura I. O processo de cuidar, como um todo, pode contribuir para o ensino de enfermagem, porém as fases Que, em geral, se sucedem Quanto à realização de alguma atividade por parte da cuidadora com o paciente serão privilegiadas, a saber, as fases de percepção, identificação da situação, ação propriamente dita e resposta ${ }^{(15)}$.

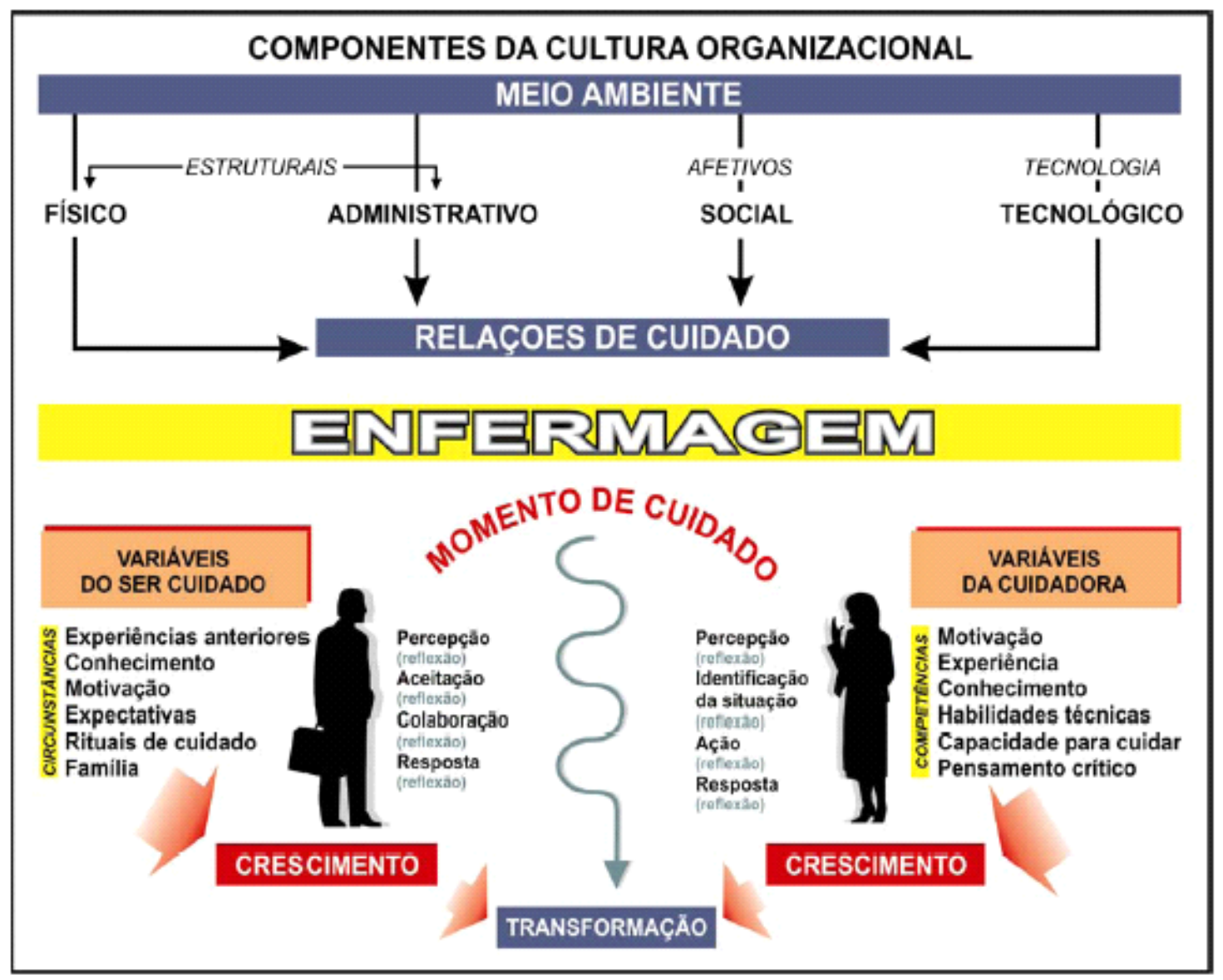

Figura 1. Representaçāo gráfica do processo de cuidar. 


\section{A PRÁTICA REFLEXIVA}

Estudos apontam para uma tendência Que é a aquisição e aplicação do conhecimento na prática ${ }^{(1,8)}$. Uma das sugestões para melhorar, tanto a prática acadêmica como a prática profissional, refere-se ao Que se denomina de prática reflexiva ${ }^{(1,2,9)}$. A maioria desses estudos se apóiam em Schön ${ }^{(10,11)}$ Que propõe uma nova epistemologia da prática tomando em consideração, principalmente, o Que expressou como reflexão-na-ação.

A enfermagem, por sua natureza essencialmente prática, pode se beneficiar muito com essa tendência de refletir sobre a prática. Existe, contudo, duas tendências Que se aproximam: uma é a de refletir a prática como um todo e Que tem como meta principal, transformar a prática ${ }^{(9)}$; outra é a de refletir sobre o Que se está fazendo e Que, por sua vez, pode incluir: 1) uma reflexão-na-ação enQuanto está sendo realizada a ação( ${ }^{(10,1)} ; 2$ ) outra forma é a reflexão-sobre-a-ação Que significa refletir sobre a ação Que foi realizada $^{(7)}$. Refletir sobre as experiências favorece olhar para dentro e ver a si próprio, confrontando o Que se Quer com o Que se faz. Isso faz com Que se consiga entender as contradições entre o que é desejado e o que é, na verdade, realizado em nosso cotidiano profissional. O conflito Que inevitavelmente surge provoca uma reação, ou seja, faz com Que se busQuem meios para resolver as contradições, portanto fortalece e encaminha para a ação Que, em geral, é a de mudança ${ }^{(12)}$. Este refletir sobre a experiência equivale à reflexão-na-ação, porém apresenta uma diferença Que é a sua natureza fenomenológica. Envolve a experiência vivida e trata-se mais de uma reflexão pessoal, incluindo análise de valores e princípios e, desta forma, as visões de mundo podem ser reconsideradas, levando a transformação ${ }^{(12)}$.

Há autores ${ }^{(16)}$ Que rejeitam a viabilidade de refletir-na-ação, argumentando Que nessa modalidade a situação é mudada; este tipo de reflexão enquanto é realizada a ação é mais rara e requer uma atitude introspectiva. A reflexão-sobre-a-ação, por sua vez, é sempre retrospectiva e, na Enfermagem, é o tipo Que mais comumente acontece ${ }^{(16)}$.

Estudo $^{(7)}$ realizado utilizando narrativas (sob a perspectiva de incidentes críticos) por parte de enfermeiras em situações críticas é referido como sendo reflexões-sobre-as-ações, portanto, sobre ações já realizadas ${ }^{(16)}$. Essa retrospectiva, no entanto, revela Que durante as ações as enfermeiras mudaram suas atitudes e modificaram o curso de algumas ações conforme julgaram mais adequado para aquele momento Estas mudanças, provavelmente foram fruto de reflexão-na-ação. As narrativas evidenciaram Que atitudes foram tomadas as Quais não estavam previstas nos planos de enfermagem, denotando Que foram decorrentes das circunstâncias como se apresentavam no momento. Cumpre destacar que esse fato, de agir fora do planejado, é uma das justificativas de vários autores em relação ao processo de Enfermagem, pois as decisões clínicas ou julgamentos clínicos são necessários no momento e nem sempre podem ser previstas com antecedência $^{(7-9)}$. O profissional precisa usar o "saber o Quê" (know that ), Que é o conhecimento teórico, e mais o "saber como" (know how), Que é o conhecimento prático, para agir na hora, com conhecimento e presteza ${ }^{(7)}$.

É importante ressaltar Que o processo de refletir-na-ação pode gerar conhecimento, pois o profissional ao refletir o Que está fazendo e na situação como um todo (na ação propriamente dita, na reação do paciente, no ambiente, etc), estará testando (habilidades, técnicas, teorias), emitindo hipóteses e julgamentos e já estará planejando, prevendo atitudes ou mudanças futuras Quando já não forem realizadas no momento.

\section{A REFLEXÃO-NA-AÇÃO}

É costume executarmos nossas atividades do dia a dia sem pensar a respeito, ou pelo menos, não enQuanto se está atuando. Não é uma atividade rotineira refletir sobre o Que se está fazendo exatamente no momento da ação. Não é incomum, todavia, nos depararmos com surpresas, Que tanto podem ser agradáveis Quanto desagradáveis ${ }^{(1)}$. Ocorre Que para não sermos surpreendidos com situações embaraçosas e para buscar melhorar a nossa prática profissional, a reflexão acerca da prática é aconselhável. Caso contrário corremos o risco de robotizar nossas ações, tornando os atos mecânicos, automáticos, recaindo em uma rotina. Na realidade de hoje isso é bastante perigoso, pois vivemos em um mundo Que sofre constantes mudanças e profissionais são desafiados a atualizarse, buscando inovar suas práticas para não sofrerem o risco de serem superados.

Refletir o Que se faz visa atualizar, renovar, simplificar, tornar melhor e mais eficiente. Ao se refletir-na-ação existe a vantagem (diferentemente do Que pensa Rolfe ${ }^{(16)}$ de se interferir na situação em desenvolvimento. Por outro lado, a reflexão possibilita, além de adQuirir maior conhecimento sobre a prática e as ações nela envolvidas, gerar novos conhecimentos.

O profissional Que adota a prática de refletir suas ações tornase um aprendente de sua própria performance. Ele pensa sobre como poderia fazer diferente e melhor e, como já referido anteriormente, construir teorias, novas técnicas, testar hipóteses e modificar suas ações "in locu". Para tal é necessário dedicação e concentração. Dessa forma a reflexão-na-ação serve para focalizar a atenção do profissional aQui e agora, assim como na singularidade de sua relação com o paciente, a Qual pode ser considerada uma experiência enriquecedora. Por outro lado, ocorre uma redução da monotonia já Que, por vezes, pode ocorrer desgaste pelas tarefas desenvolvidas, o Que poderá ser minimizado ${ }^{(16)}$.

Uma característica da reflexão-na-ação é Que ela propicia um rompimento com a racionalidade técnica, tradicionalmente predominante nos currículos de enfermagem. Embora uma atividade prática, tende-se a racionalizar as situações na enfermagem e acabase anulando as subjetividades e a importância da experiência vivida pelos sujeitos, tanto os Que sofrem as ações, Quanto os Que as executam. Deve-se lembrar Que o conhecimento prático deve ser holístico e pessoal ${ }^{(1)}$.

A reflexão-na-ação aciona o conhecimento tácito, a intuição, aQuele conhecimento que está latente e não consegue ser explicado. Conhecer-na-ação é a expressão Que revela o conhecimento "inteligente"( II) ou conhecimento implícito na ação e que dificilmente pode ser descrito. É um conhecimento que significa Que se sabe muito mais do Que se pode expressar e na Enfermagem é bastante comum não se saber explicar o Que se sabe e como se sabe; profissionais se deparam com situações em Que reconhecem um fenômeno (um paciente experimentando uma situação particular, por exemplo) e, contudo não sabem descrever como e por Que o 
reconheceu. Muitas ações são empreendidas em decorrência a esse reconhecimento ${ }^{(7)}$.

\section{A REFLEXÃO-NA-AÇÃO NO MOMENTO DO CUIDAR}

Será enfocada, a seguir, a reflexão Que ocorre por parte da cuidadora, embora ela seja prevista ocorrer também por parte do ser cuidado ${ }^{(17)}$. Embora importantes e necessárias as informações sobre a experiência Que o paciente vivencia em relação à doença, o cuidado e a hospitalização, as reflexões do ser cuidado não têm as mesmas implicações e não podem ser trabalhados como um instrumento ou estratégia para a prática.

Conforme pode se acompanhar pela figura, a cuidadora ao cuidar percebe a situação como um todo e o processo reflexivo já inicia nessa fase; indagações como as Que se seguem podem servir de guia: Que situação é essa? Como se caracteriza? Quem é esse paciente? Qual é sua história? O Que mais preciso saber sobre ele e sua condição? Como poderei ajudá-lo? È uma pré-reflexão, antes mesmo de encontrar o paciente e, evidentemente, antes mesmo da ação. Esta pré-reflexão deve ocorrer com o objetivo de preparar as condições para iniciar a ação, seja um procedimento, seja para conhecer melhor o paciente, para informar-se sobre o Que o paciente deseja, suas expectativas, etc. Com os Questionamentos como os acima, a cuidadora poderá atender as indagações, dúvidas e hipóteses Que o paciente venha a apresentar durante um específico momento no processo de cuidar ou durante todo o processo, enQuanto sujeito de cuidado.

Antes de iniciar a ação de cuidar propriamente dita a cuidadora, frente ao Que já levantou na fase anterior, identifica o tipo de cuidado necessário, Quando deverá ser desenvolvido (embora se considere Que o cuidado sempre estará presente, mesmo na ausência de QualQuer ação) e o Que será preciso para o mesmo, tais como: condições materiais, eQuipamentos, condições estruturais, além de certificar-se de suas próprias condições pessoais para realizar a ação. Isso inclui o início da interação interpessoal, expressão de reconhecimento e aceitação do paciente e sua condição. Inclui disponibilidade, acolhimento, respeito, presença (estar - com e ser-com-o paciente).

lá tendo providenciado tudo o Que seria necessário e desejável (material, privacidade, segurança, limpeza e demais condições ambientais para a realização do cuidado), a cuidadora inicia a ação, preferentemente comunicando-se com o paciente, seja por meio de palavras, seja por meio de gestos, postura ou mesmo, silêncio. Saber ouvir já é um cuidado eficaz.

A reflexão-na-ação então se caracteriza por alguns Questionamentos úteis, tais como: Como se apresenta a situação? Os meios estão sendo adeQuados? Precisarei modificá-los? Como o paciente está reagindo? È uma reflexão Que já conota, inclusive, uma espécie de avaliação crítica sobre o Quê e como está se processando a ação. Nesse sentido também pode ser Questionado: O Que posso fazer para tornar a situação, condição do paciente mais confortável? Como esta situação está me afetando? Como estou me sentindo? Algo no entorno necessita de ajustes? No Que esta ação se distingue como de cuidado? O Que significa o cuidado para mim? E assim por diante. No caso de um curativo, por exemplo, a cuidadora poderá refletir, emitindo as seguintes perguntas: Que tipo de ferida é esta? Que tecidos estão envolvidos? Como se apresenta em termos de estrutura, coloração, cheiro, secreções, tecidos adjacentes, etc? Como está se processando a cicatrização? As medidas terapêuticas estão surtindo efeito? Seria necessária alguma modificação como, por exemplo, fręüência, material a ser utilizado, horário de realização, posição, aplicação de algum medicamento? Como poderei descrever esta ferida para a eQuipe?

Como já se mencionou antes, a cuidadora poderá modificar a ação conforme julgar necessário e conforme sua reflexão acerca do Que está acontecendo. Ela pode intervir pessoalmente ou solicitar ajuda para Que a ação se concretize da forma mais adeeuada possível.

Após a realização da ação ocorre a reflexão-sobre-a-ação: o Que foi feito, como foi feito, Quem executou a ação, as reações do paciente, dos familiares Quando presentes, as condições ambientais, materiais, assim como refletir sobre os seus próprios valores e sentimentos em relação à situação. Os elementos e dados resultantes da reflexãona-ação são retomados de forma a avaliar todo o momento; a cuidadora faz uma avaliação geral do evento e sobre como cada componente envolvido se comportou. Essa reflexão auxilia no aprendizado, na atualização dos cuidadores e contribui para a eualidade do cuidado. Por outro lado, tem como objetivo verificar a resposta do paciente, pois se o cuidado foi positivo, a confiança do paciente é conquistada ou mantida, assim como a credibilidade com o cuidado prestado. Por cuidado positivo entende-se aquele em Que além da intervenção realizada com competência, houve uma interação favorável, franca, de aceitação e respeito mútuo ${ }^{(17)}$.

\section{IMPLICAÇÕES PARA O ENSINO}

Refletir-na-ação e refletir-sobre-a-ação podem ser estimuladas. Algumas estratégias podem ser utilizadas para Que esse processo seja nutrido e desenvolvido, principalmente as concernentes as atividades de tomada de decisão ou julgamento clínico $^{(8)} \mathrm{e}$ pensamento crítico $^{(18)}$. Destaca-se um trabalho recente, realizado por alunas de um curso de graduação em Enfermagem utilizando pensamento crítico $^{(19)}$. As estudantes, responsáveis pelo trabalho, referem terem sido estimuladas a trabalhar o pensamento crítico o Que as levou a despertar e criar habilidades para pensar e tomar decisões Que julgam Ihes beneficiará no futuro, já como profissionais, a tomarem decisões mais rápidas e eficientes.

Processo de enfermagem, resolução clínica de problemas, raciocínio diagnóstico, tomada de decisão clínica, julgamento clínico e pensamento crítico são, por vezes, usados de forma idêntica. Realmente algumas dessas atividades apresentam algumas similaridades. A maioria se caracteriza por apresentar um processo racional deliberado Que, com freeüência, podem limitar a capacidade para captar aspectos importantes e, por vezes, sutis das experiências da prática de enfermagem e Que não podem ser percebidos através daqueles métodos. O processo de enfermagem, principalmente, assim como o processo de estabelecimento diagnóstico e resolução de problemas, sugerem um problema a ser solucionado ${ }^{(8)}$. Autores referem Que, por exemplo, o julgamento clínico refere-se a modos nos Quais as cuidadoras vêm a entender os problemas, preocupações e Questões Que dizem respeito ao bem-estar do paciente, reconhecendo informações críticas e respondendo as circunstâncias de forma interessada e compromissada ${ }^{(8)}$. O pensamento crítico, embora mais 
frequentemente utilizando um modelo dentro dos pressupostos da racionalidade técnica, apresenta uma vertente em Que as Questões interativas, afetivas, sociais e políticas podem ser trabalhadas de forma holística ${ }^{(18)}$.

Estudantes de enfermagem buscam aplicar o conhecimento teórico na prática, porém as experiências no campo clínico nem sempre correspondem ao esperado; são comuns Queixas sobre desarticulação entre teoria e prática. Este é um problema complexo e embora a teoria seja importante, as experiências práticas do campo clínico fornecem uma aprendizagem bem mais completa. A vivência clínica envolve uma série de elementos Que a teoria não consegue contemplar tais como: 1) obter sentido de self como cuidadora; 2) lidar diretamente com a tecnologia e com o ser humano; 3) atuar e negociar com os profissionais de campo; 4) aprender e captar o significado de cada situação como um todo; 5) enfrentar o sofrimento e a morte; 6) lidar e aprender com o envolvimento; 7) aprender e lidar com a própria ansiedade, medo e insegurança; 8) captar a dinâmica da prática -desenvolvendo habilidades, descobrindo as capacidades pessoais, assim como as dos pacientes e familiares, aprendendo a observar, a centrar-se e a experienciar o ritmo da unidade ${ }^{(8)}$.

A experiência e o preparo do docente são fundamentais para favorecer o desenvolvimento da habilidade reflexiva ou pensamento crítico ou Qualeuer outra atividade para facilitar o processo reflexivona-ação e sobre-a-ação. Observar e acompanhar profissionais experientes no campo clínico, experienciar situações e condições semelhantes por parte dos pacientes são também sugeridas, além de dispender maior tempo na prática de forma a possibilitar o máximo da vivência da dinâmica do cenário clínico e familiarizarse com ele. Simulações, vídeos interativos e muita troca de experiência podem ajudar, tais como o uso de diários e narrativas para acionar o processo reflexivo; exercícios, Questões guias para refletir as experiências, incidente crítico, entre outras estratégias são sugeridas também ${ }^{(8,18)}$.

Há uma forte associação entre o desempenho e a experiência

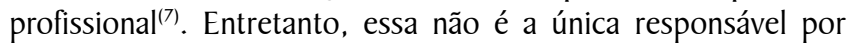
atitudes e decisões mais eficientes; o envolvimento, a capacidade de centramento e, principalmente a capacidade de extrair significado das experiências são fatores marcadamente influentes. Daí se conclui Que o professor engajado, envolvido e interessado, acrescido do preparo, torna-se um fator imprescindível. Ele é um líder do processo ensino-aprendizagem, porém sempre disposto a aprender também; é um parceiro, um facilitador; um cuidador.

\section{CONSIDERAÇÕES FINAIS}

Tratados neste texto, de forma breve, a prática reflexiva, principalmente no Que tange a reflexão-na-ação Que significa refletir o Que se faz enquanto se está fazendo.

A Enfermagem se caracteriza por ser eminentemente uma atividade prática e o processo de cuidar como apresentado prevê, no momento de cuidar, a reflexão-na-ação. A reflexão, seja no momento da ação de cuidar ou após sua realização, é uma atividade Que não é muito comum na literatura de enfermagem na nossa realidade, tampouco como tema de pesQuisa ou como relato de experiência. A reflexão Quando adotada, deveria ser um exercício regular, realizado de forma sistemática para conduzir a mudanças (2). Por outro lado, ela propicia Que o profissional ou aluno mantenham-se sempre alertas intelectualmente.

Vários autores remetem a influência do papel docente e sua prática pedagógica na Enfermagem e da necessidade do preparo docente para utilizar e desenvolver a reflexão nos alunos ${ }^{(1,20)}$. Docentes precisam redirecionar sua atuação de forma a se tornarem práticos reflexivos e pes@uisadores de sua própria prática ${ }^{(2)}$.

Como se viu e vale a pena reforçar, o conhecimento necessário para demonstrar competência profissional em uma atividade prática pode ser percebido como de natureza artística, mais do Que técnica e se caracteriza por ser um conhecimento de ordem pessoal e prático, ou seja, um conhecimento-na-ação e este, como já comentado no início do texto, pressupõem um saber tácito o Qual é ativado na própria ação ${ }^{(1,10)}$.

Finalmente, a prática reflexiva, como se sugere, propicia atualização, renovação, simplificação de técnicas e procedimentos, gerando novos conhecimentos, além de contribuir na reformulação de valores e melhoria das interações no ambiente de trabalho, sem contar a Qualidade do cuidado.

\section{REFERÊNCIAS}

I. Moya JLM, Parra SC. La enseñanza de la enfermería como una práctica reflexiva. Texto Contexto-Enferm 2006; I5(2).

2. Rodrigues MTP, Mendes Sobrinho IAC. Enfermeiro professor: um diálogo com a formação pedagógica. Rev Bras Enferm 2007; 60(4): 456-9.

3. Pereira RCI. Tendências na educação de Enfermagem. Rev Gaúcha Enferm 1989; 10(2): 45-9.

4. Pereira $\mathrm{RCI}$. Desenvolvendo o pensamento crítico nas Questões do ensino e da prática da Enfermagem. Rev Gaúcha Enferm 1992; 13(1): 24-7.

5. Waldow VR. Reflexões sobre o ensino de Enfermagem. Rev Gaúcha Enferm 1989; 10(2): 4l-4.

6. Waldow VR. Desenvolvimento de pensamento crítico na enfermagem. In: Waldow VR, Lopes MIM, Meyer DE. Maneiras de cuidar, maneiras de ensinar: a enfermagem entre a escola e a prática profissional.Porto Alegre: Artes Médicas; 1995.

7. Benner P. From novice to expert: excellence and power in clinical practice. Menlo Park: Addison-Wesley; 1984.

8. Tanner CA. Rethinking clinical judgement. In: Diekelmann NL, Rather ML, editors. Transforming RN education: dialogue and debate. New York: National League for Nursing; 1993.

9. Johns C, Freshwater D. Transforming nursing through reflective practice. Malden: Blackwell Science; 1998.

10. Schön DA. The reflective practitioner:how professionals think in action. New York: Basic Books; 1983.

11. Schön DA. Educando o professional reflexivo: um novo design para o ensino e a aprendizagem. PortoAlegre: ARTMED; 2000.

12. Johns $\mathrm{C}$. Opening the doors of perception. In: JohnsC, Freshwater D, editors. Transforming nursing through reflective practice. Malden: Blackwell Science; 1998.

13. Sena RR, Silva KL, Gonçalves AM, Duarte ED, Coelho S. O cuidado no trabalho em saúde: implicações para a formação 
de enfermeiros. Interface 2008; 12(24): 23-34.

14. Souza ACC, Muniz Filha MJM, Silva LF, Monteiro ARM, Fialho AVM. Formação do enfermeiro para o cuidado: reflexões da prática profissional. Rev Bras Enferm 2006; 59(6): 805-7.

15. Waldow VR. Bases e princípios do conhecimento e da arte da Enfermagem. Petrópolis: Vozes;2008.

16. Rolfe G. Beyond expertise: reflective and reflexive nursing practice. In: Johns C, Freshwater D, editors. Transforming nursing through reflective practice. Malden: Blackwell Science; 1998.

17. Waldow VR. Cuidar: expressão humanizadora da Enfermagem.
Petrópolis: Vozes; 2006.

18. Waldow VR. Estratégias de ensino na Enfermagem:enfoque no cuidado e no pensamento crítico. Petrópolis: Vozes; 2005.

19. Lorenzetti FS, Kaiser MJ. Sistematização da Assistência de Enfermagem na UTI: enfoque paradigmático da prática do cuidar em enfermagem [monografia]. Lages: Escola de Enfermagem, Universidade do Planalto Catarinense; 2008.

20. Madeira MZA, Lima MGSB. A prática pedagógica das professoras de enfermagem e os saberes. Rev Bras Enferm 2007; 60(4): 400-4. 